\title{
REDUCED RADIATION DOSE OF THORACIC AND CARDIAC DUAL SOURCE COMPUTERTOMOGRAPHY WITH HIGH-PITCH PROTOCOL IN INFANTS AND CHILDREN
}

\author{
H.G. Kehl ${ }^{1}$, D. Kiski ${ }^{2}$, D. Maintz ${ }^{3}$, D. Stege ${ }^{1}$, V. Debus ${ }^{1}$, S. Kotthoff ${ }^{1}$, H. Seifarth ${ }^{3}$ \\ ${ }^{\text {I} P a e d i a t r i c ~ C a r d i o l o g y, ~}{ }^{2}$ Paediatics, ${ }^{3}$ Clinical Radiology, University Hospital of Muenster, Münster, \\ Germany
}

Objectives: To investigate the feasibility and the image quality of thoracic and cardiac dual source CT (DSCT) with ultra-low radiation in infants and young children without sedation.

Methods: Between October 2009 and December 2010 DSCT were performed in 71 patients (age: 2 days - 5 years). The spiral scans were done with a pitch of 3.0 in all examinations. The parameters of the scan protocol used in thoracic examinations without contrast agent were $80 \mathrm{kV}, 10 \mathrm{mAs}$ with modulation, in cardiac CT with contrast agent $(2 \mathrm{ml} / \mathrm{kg})$ they were $100 \mathrm{kV}, 30 \mathrm{mAs}$ with modulation. Image reconstructions were done with iterative algorithms, a slice thickness of $0.75 \mathrm{~mm}$ was chosen. For each examination the effective radiation dose was calculated using the actual parameters of the scanner.

Results: In thoracic CT without contrast enhancement $(n=40)$ the mean radiation dose was $0.48 \pm 0.22 \mathrm{mGy}$, according to an effective dose of $0.35 \mathrm{mSV}$. In contrast enhanced cardiac $\mathrm{CT}(\mathrm{n}=31)$ the mean radiation dose was $0.97 \pm 0.26 \mathrm{mGy}$, according to an effective dose of $0.86 \mathrm{mSV}$. The scan time varied from 0.5 to 1.2 seconds. Image quality was useful in all examinations. Artifacts from breathing did not occur. 3D reconstructions from contrast enhanced CT could be done easily.

Conclusions: DSCT with high-pitch protocol in infants and children saves radiation dose, permits fast cardiac examinations without sedation, and provides superior 3D visualization of congenital heart defects. 